Research Article

\title{
Structural Characterization of an Historical Building by Means of Experimental Tests on Full-Scale Elements
}

\author{
Marco Bovo, Claudio Mazzotti, and Marco Savoia \\ Department of Civil, Chemical, Environmental and Materials Engineering (DICAM), University of Bologna, \\ Viale Risorgimento, 2-40136 Bologna, Italy \\ Correspondence should be addressed to Marco Bovo; marco.bovo@unibo.it
}

Received 1 August 2017; Accepted 3 October 2017; Published 19 December 2017

Academic Editor: Pier Paolo Rossi

Copyright () 2017 Marco Bovo et al. This is an open access article distributed under the Creative Commons Attribution License, which permits unrestricted use, distribution, and reproduction in any medium, provided the original work is properly cited.

In order to properly design strengthening intervention of existing buildings, careful assessment of the structural behavior is certainly required. This is particularly important when dealing with historical constructions made of heterogeneous materials like masonry or stonework. In this context, this paper presents the results of knowledge process on a large monumental nineteenth century building located in Trieste. The traditional investigation approach considering a wide number of destructive tests for characterization of materials and evaluation of the structural details were not admissible due to the valuable cultural and historical importance of the building. Therefore, an alternative and not conventional investigation approach has been considered. After a wide historical research and a detailed structural survey, it has been possible to identify the main structural systems of the building. Then, to characterize the structural response, a limited number of nondestructive tests but on full-scale typological systems have been preferred to a larger number of destructive tests on specimens of the different materials. The selected experimental load tests have been conducted in order to assess the actual structural response of the main systems that constitute the building, thus allowing for a fine tuning of both the rehabilitation interventions and the numerical finite element models.

\section{Introduction}

When dealing with existing buildings, the request of knowledge is one of the most important aspects to be considered for the purposes of both a reliable evaluation of the current safety level and for an effective design of interventions for the preservation of the buildings themselves. In fact, for monumental heritage, an appropriate level of knowledge of the building allows for the definition of the most suitable intervention class, able to reduce at minimum its impact and possible negative effects, and, if possible, for the selection of a reversible intervention. On the other hand, when considering the point of view of the structural safety in the context of a renovation design or seismic strengthening of an existing building, a careful judgment on the current structural behavior and on load-carrying capacity of the principal elements is required. Stonework buildings may have good performances in the case of seismic events, and in particular, a sufficient ductility capacity, even if associated with a widespread state of damage [1-3].
Moreover, the real structural behavior is often far from that predicted by conventional structural models or practices $[4,5]$. These aspects are particularly important for structures that are abandoned since many years, and the deterioration process due to environmental factors can be in an advanced state [6-8]. To this purpose, the knowledge procedure can act on different levels of detail, depending on the accuracy of geometric survey, historical research, and experimental investigations. Several and different investigation techniques have been developed in the last years, and it is therefore necessary to plan the investigation analysis properly, by selecting the more appropriate procedure. A structural investigation can be based on nondestructive tests (NDTs), minor destructive tests (MDTs), and destructive tests (DTs). Given the historical value of the building considered, NDTs (such as thermography and sonic and X-ray tests) and MDTs (such as endoscopy and core drill sample) should be preferred to other more invasive techniques, even if almost only qualitative information can be obtained from the former. In a design 


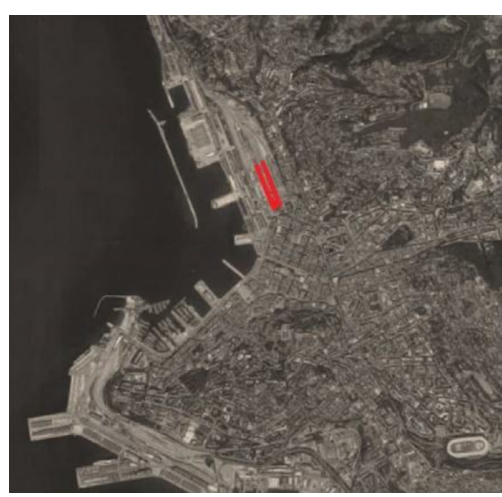

(a)

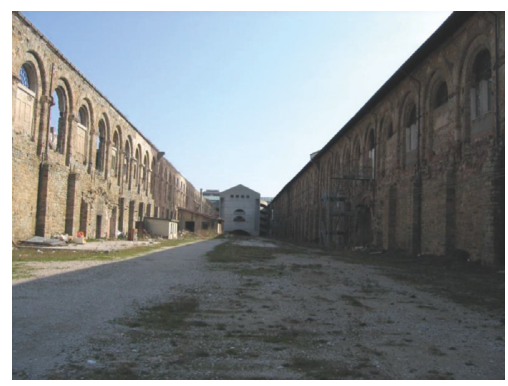

(d)

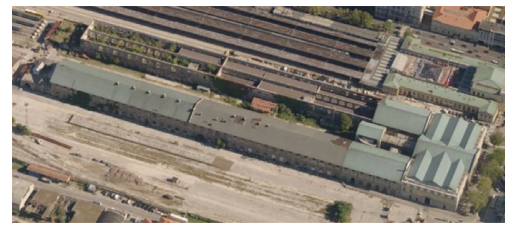

(b)

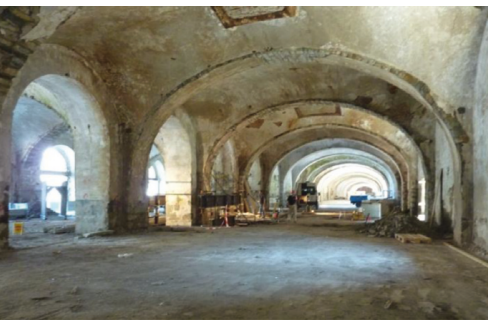

(e)

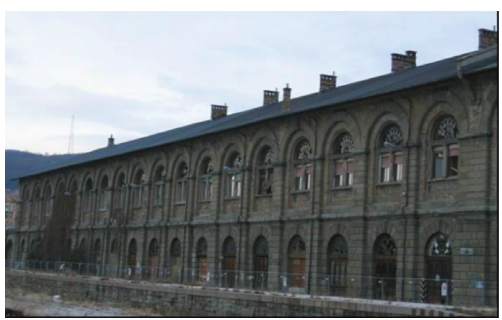

(c)

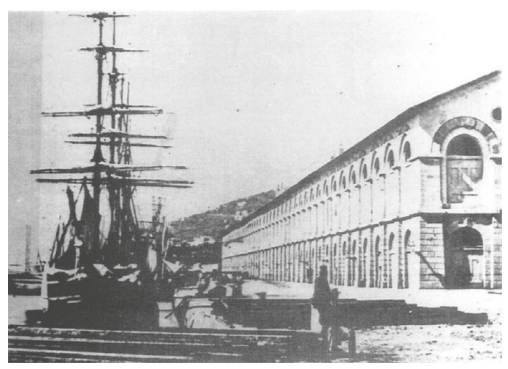

(f)

Figure 1: The nineteenth century "ex-Silos" storehouses of Trieste: (a) location in the harbor area; (b) aerial view; (c) lateral (sea side) view; (d) view of inner courtyard; (e) internal view of the arches-vaults system at the ground floor; (f) seaside view of the buildings from an historical ancient picture.

process involving rehabilitation and strengthening intervention, a preliminary material investigation through DTs is often required [9], while further MDTs or NDTs allow for a more detailed analysis of the interaction between different structural parts of the system. The behavior of historic stonework, in particular, depends on many factors; the most important being the geometry of the structure, shape and strength of the stone, thickness of mortar layers, and interface cohesion between the mortar and the stone $[10,11]$. In this perspective, for a suitable knowledge of the structure, an extended in situ survey and an experimental campaign are usually strongly recommended [12-14] to obtain more affordable information on material characteristics and structural behavior.

In the present paper, the main results of an experimental campaign devoted to the knowledge and characterization of the structural behavior of the large masonry building known as "ex-Silos storehouses" (sited in Trieste) are presented. This monumental construction, shown in Figure 1, was built in the nineteenth century to collect and store the wheat coming from the Trieste harbor. It is a twostorey building, constituted of thick longitudinal stonework walls and series of transversal stone arches connected by means of brickwork vaults. At present, it is in an advanced state of deterioration, and a huge restoration project is undergoing, aimed at the realization of a new shopping centre and urban facilities.
The "ex-Silos" with its storehouses is both architecturally and historically of interest, and the complex is nowadays under the protection of the Italian Historical Preservation Office for monumental building. As a consequence, the traditional investigation approach considering a wide number of DTs for the characterization of materials and evaluation of the structural details was not possible.

Therefore, authors consider an alternative and not conventional approach by involving a preliminary very indepth study of historical documentation of the building followed by a careful geometrical building survey. Starting from the outcomes of this first phase, it has been possible to identify the main structural elements and evaluate the portions of the building in which the interaction between structural elements could modify the expected bearing mechanism (i.e., the interaction between transverse arches and vaults or longitudinal walls). To characterize the structural response of the building, a limited number of NDTs but on full-scale typological systems (e.g., transverse arches, perimeter walls, and foundation system of the columns) have been preferred, instead of the typical approach based on a higher number of local measures coming from DTs on specimens of the different materials (i.e., mortar, stone, and brick). In this way, it has been possible to capture the global behavior of the subsystem (i.e., transverse main arches, perimeter walls, central longitudinal arches, and vaulted floor depicted in Figure 2(c)) that constitutes the wings of the storehouses. This was possible, thanks to the 

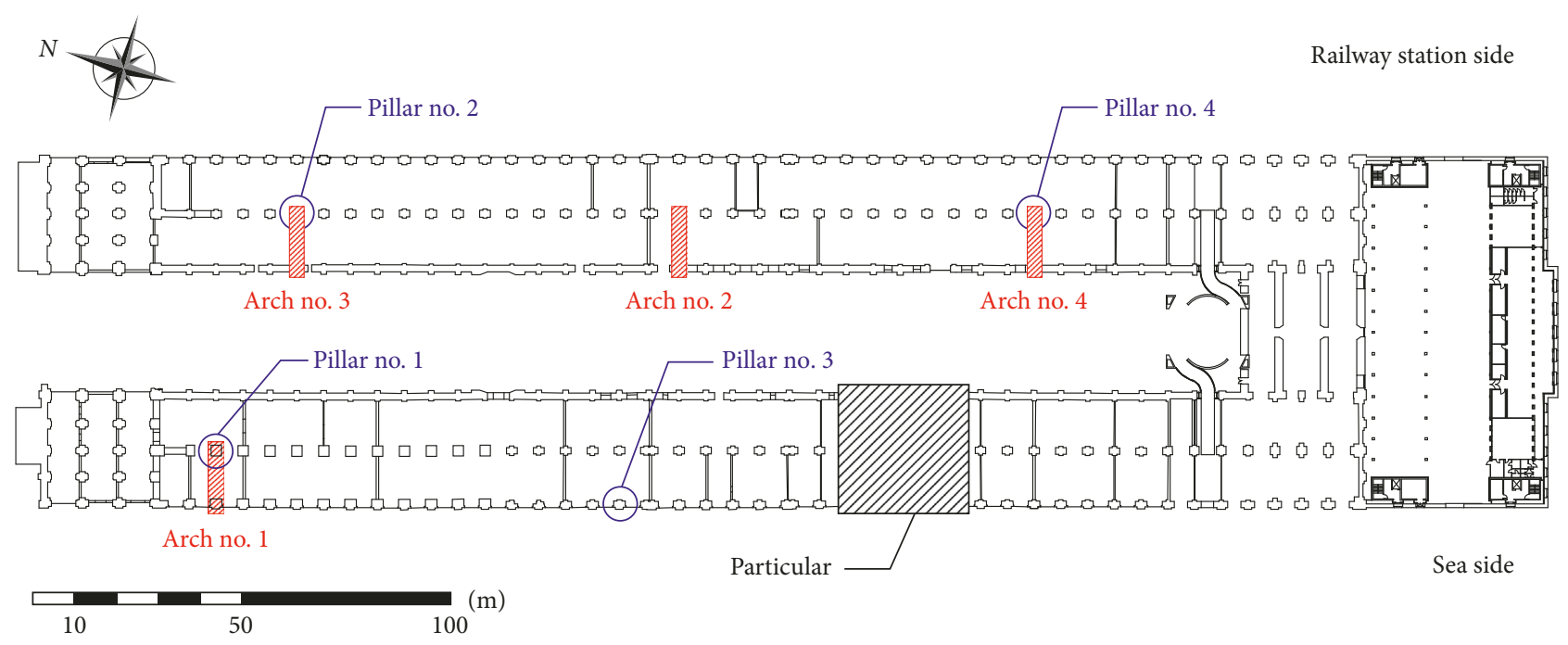

(a)

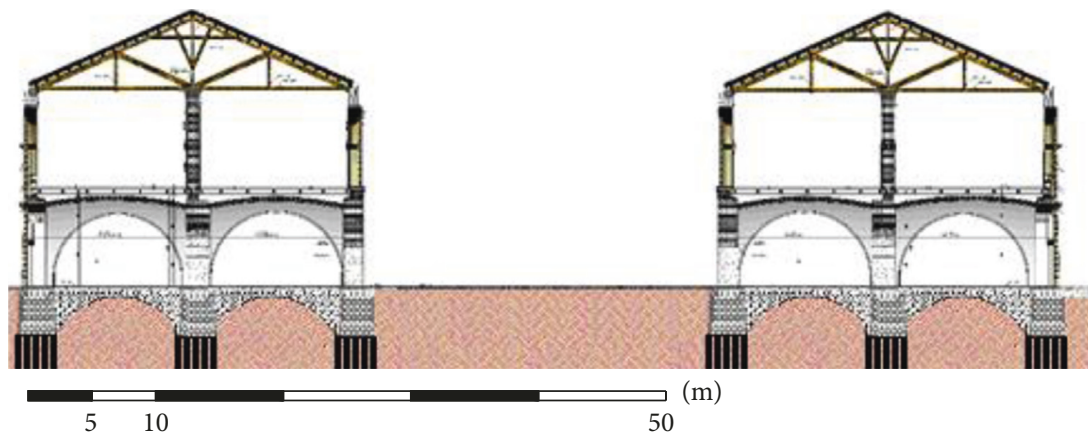

(b)

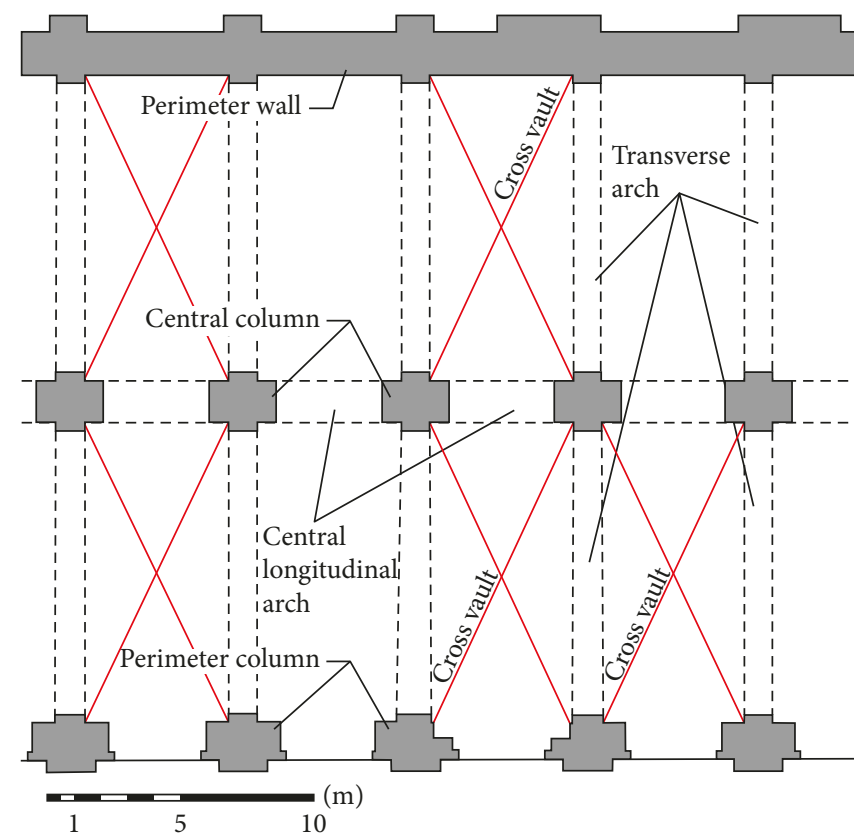

(c)

FIGURE 2: Geometrical survey of the building: (a) plan of the ground floor; (b) typical transversal section; (c) particular of the bearing structural system. 
repetitiveness of the elementary module of the building object of the study.

In the framework of the approach introduced, a series of experimental full-scale load tests have been conducted in order to assess the actual structural response of the main systems that constitute the building, thus allowing for a finetuning of both the rehabilitation interventions and the numerical finite element models.

For a complete characterization of the behavior of the various structural systems analyzed, different kinds of tests have been conducted, at different scale levels.

As for stone arches, in situ NDTs have been carried out with the purpose of investigating their structural response under different types of loading conditions $[15,16]$. The arches have been tested with symmetric and asymmetric static loading configurations first, and then with dynamic excitations, in order to assess the corresponding key parameters of the structural system. Finally, in order to characterize also the behavior of the foundation system, four column bases have been tested with increasing vertical loadings. With reference to stone masonry walls, the mechanical properties have been obtained by tests on both stone-cored specimens and fullscale stonework walls tested under compression in laboratory. These DTs were not avoidable or replaceable with NDTs or MDTs due to the large dimensions of the stones and the irregular masonry texture. Nevertheless, their number was kept at a minimum, and other NDTs have been conducted to assess the masonry homogeneity throughout the building [17]. At the same time, the more invasive DTs (e.g., diagonal compression test for the assessment of the shear strength of the wall investigated) were not possible due to the widespread damage scenario that they could induce in a large number of walls, all this resulting incompatible with the prescriptions of the Italian Historical Preservation Office for monumental buildings.

From the experimental tests, very useful information on the structural response has been obtained, and the outcomes allowed to properly define the numerical finite element models to adopt for the design of restoration interventions required from the loading levels associated with the new intended use of the construction.

\section{The Building and Its Historical Events}

The present paper concerns the structural behavior of a huge monumental building, known as "ex-Silos storehouses," arranged on two levels, for a total surface of about 36,000 square meters. The building, in a critical state of preservation and in an advanced state of deterioration, is located in the Trieste city centre and is currently subject to a huge restoration project aimed at the realization of a new shopping centre and urban facilities. The knowledge process of the structure started with an extended historical research useful to identify the information concerning the age of the building, the materials adopted in the construction process, the criteria of the original design, and the modifications introduced in the service life of the storehouses.

The storehouses, made with Istria's sandstone masonry, are constituted by two parallel rectangular buildings $316 \times 27$ meters (length $\times$ width) each and about 20 meters high (at the drainpipe level). These two buildings enclose an inner courtyard of about $270 \times 29$ meters (Figure 1).

The buildings were built from 1840 to 1850 , during the Habsburg dominion, and his history is strictly related to the laying of Southern Railway linking Ljubljana to Trieste. The buildings were realized between the railway station and Trieste harbor, in the northern edge of city boundaries, near St. Teresa's Lazaretto and the old Butchery, which is the area alongside New Lazaretto Street. On July 27, 1857, in the presence of the emperor Francesco Giuseppe, an opening ceremony of the last stretch of the railway Ljubljana-Trieste gave the start-up of the storehouses' activity.

They were designed to collect and store the wheat transported by train and to ship it by sea. The ground floors of each storehouse were used as bonded warehouses.

In order to facilitate the transportation and the stowing of wares, in the pristine version, the storehouses were built with the upper floor at 10.12 meters above sea level and with five freight train tracks laid at the same level up to the internal courtyard. A set of hydraulic lifts allowed the transportation of goods between the two floors.

After few years, the station and the storehouses turned out to be insufficient and unsuitable for the developing Trieste's trades. Eight years after the opening ceremony, the station manifested also some design deficiencies, corrected by lowering the inner square and the freight trains arrival from 10.12 meters level to the seashore level (3.16 meters).

In the storehouses, in place of the existing administrative offices, the engineer Gustav Lahn designed a new transversal building, constructed in 1865 on three floors. This building, of about $45 \times 84$ meters and known as "Silos", differs from the ancient buildings because it has rectangular windows instead of arched openings and a big pediment on the façade with a middle rose window. Wilhelm Flattich's project replaced Lahn's, and the station changed its look again. Taxfree port, which was in force since 1719 , by permission of the emperor Charles VI, was abolished in 1891. Meanwhile, the existing harbor showed again his capacity limitations. After an intense use of about 30 years, with the construction of the structures of the new harbor in the South of the city, the "Silos" of the old railway station were scarcely used and progressively abandoned. After the First War period, the buildings were used as generic storehouses, while during the Second War, they were used for the rest of sorting troops at front. The "Silos" building was then put under the protection of the Italian Historical Preservation office in 1968. Moreover, two fires damaged the head "Silos" building, respectively, in 1970 and 1971. In 1975, in the occasion of a national competition announcement, the building was part of a new requalification project of the area, with possible transformation in an auditorium, urban facilities, and a shopping centre.

\section{Structural Survey of the Buildings}

A detailed structural survey of the entire storehouses was conducted as the next step of the knowledge process. The complex is composed of two main buildings with similar structural and geometric characteristics. The front building 
is not considered in the present investigation because it was not subject to the rehabilitation project and testing. The plan dimensions of the two main buildings are $316 \times 27$ meters (length $\times$ width), with a courtyard about 29 meters wide (Figure 2). The buildings have two floors about 8 and 12 meters high, respectively, for a total of 20 meters from the ground level.

The first floor has bearing perimeter walls and interior pillars arranged with a regular spacing of about 6.50 meters and connected by a series of longitudinal arches. The vertical load-bearing walls are made of very large rectangular limestone blocks, up to $30-40 \mathrm{~cm}$ long, with joints of poorly hydrated lime mortar. Moreover, on the four longitudinal façades, there are stone columns at the first floor level. The thickness of the perimeter walls is approximately 1.60 meters at the ground floor and 1.0 meter at the upper floor.

In both buildings, the first storey has stonework vaults, with a maximum height of 8 meters from the ground level. The vaults are sustained by arches in the transverse direction and by the central longitudinal arches and side walls of the façade in the longitudinal direction. The central longitudinal arches, about 2 meters thick as the bearing columns, have a span of about 6.5 meters. In the other direction, the transverse arches of the buildings have a 6.5-meter spacing (corresponding to longitudinal arch span), a span of about 12-13 meters, key brick height between 6 and 6.5 meters, and they start at 2-2.5 meters height from the ground level. Arches and columns have usually a very good texture, whereas the brick arrangement of longitudinal walls is much more irregular and often with very thick and irregular mortar layers (up to 3-4 cm high).

Transverse arches assure a considerable rigidity in transverse direction and a very high load-carrying capacity to the structure. They connect the central columns with the perimeter walls and bear both vaults and the upper woodstructure floor. At the first floor, vaults bear the load of the wooden floor, made of beams with about 1 meter of spacing, a wooden floor and, in some parts of the building, an overlying concrete slab of more recent construction. The brickwork vaults have a $40-45 \mathrm{~cm}$ constant thickness. The brickwork has a good texture, with very high compressive strength blocks and interposition of thin lime mortar joints. The intermediate vaults are tunnel vaults, except for the last three bays per building, where cross vaults are present.

For a correct description of the foundations typology and load-carrying capacity, as well as to estimate the groundwater level, a series of ground surveys were conducted under portions of perimeter walls and some column basements. The dugout excavated around the building foundations, about 3-4 $\mathrm{m}$ deep, revealed a first artificial subbase of ruins and transported soil, about 1.5 meters deep, and laid on the subgrade native material. The groundwater level, closely related to the tide levels, was found between -2.5 and $-3.0 \mathrm{~m}$.

The surveys on the thick perimeter walls showed that the stonework continues below the ground level for about 1 meter, with an enlargement of $40-50 \mathrm{~cm}$. Then, the foundation was constituted by a $70 \mathrm{~cm}$ thick layer of poor mortar, laid on a $50 \mathrm{~cm}$ thick layer of pebble and stone mixture arranged with irregular texture.
The surveys conducted on the perimeter walls highlighted stone foundations made of the same stonework as the substructure. Square-shaped stones with interposed thick joints of poor mortar are arranged in a regular way and with a series of three enlargements of about $40-50 \mathrm{~cm}$ from each side, realized $50 \mathrm{~cm}, 300 \mathrm{~cm}$, and $400 \mathrm{~cm}$ below the ground level, for a transversal size at foundation base of about 4.5 meters. Moreover, according to an historical design documentation (Figure 3), the foundation walls, at $-4.0 \mathrm{~m}$ from the ground, lay on thick stone plates supported by fir-tree piles embedded in the soil in order to improve consolidation and load-carrying capacity. This technique for improving the soil characteristics was very common in many North European countries as well as in Venice in the presence of very soft and muddy grounds $[18,19]$.

The surveys conducted on the central pillars revealed foundation structures similar to the perimeter walls, with a series of enlargements from the four edges of the section. Furthermore, the central pillar foundations are linked in the longitudinal direction by means of stone arches with irregular sections.

In order to investigate the soil stratigraphy and the geological characteristics of the site, standard penetration test (SPT) in six probing, up to about 20 meters below the ground level, was conducted in the area. The probing showed the presence of four principal layers of soils (from the ground level to depth) exhibited in Figure 3:

(i) BF1: backfill soil of recent transportation of sand matrix mixed with cobbles and demolition debris

(ii) BF2: backfill soil of ancient transportation

(iii) M: littoral marine deposits like wave-formed terrace, composed of fat clay and lens of silt with sand, with low consistency and stiffness

(iv) F: coastal rockstone flysch bank of Cenozoic era (more precisely, Eocene period), with high compactness

These outcomes are confirmed by the Geolitological Chart [20]. A vertical section of the soil stratification of the Trieste's coastal area is shown in Figure 3(a), together with the results of one of the six probings executed (Figure 3(b)).

\section{Experimental Campaign}

The experimental part of the assessment process is described in the present section, also summarizing the main results and their following interpretation. They have been organized, in three subsections with reference to the three main structural typologies of elements considered in this paper: perimeter walls of the ground level, foundation plinths, and transversal arches. The subsection concerning tests on arches is further subdivided, for the sake of clarity, into static and dynamic tests.

4.1. Tests on Wall Specimens. In order to determine in quantitative way the mechanical properties of perimeter walls, a series of compression tests on stonework largescale specimens, with dimensions $60 \times 60 \times 120 \mathrm{~cm}$ (width $\times$ thickness $\times$ height), were performed by the Structural and 


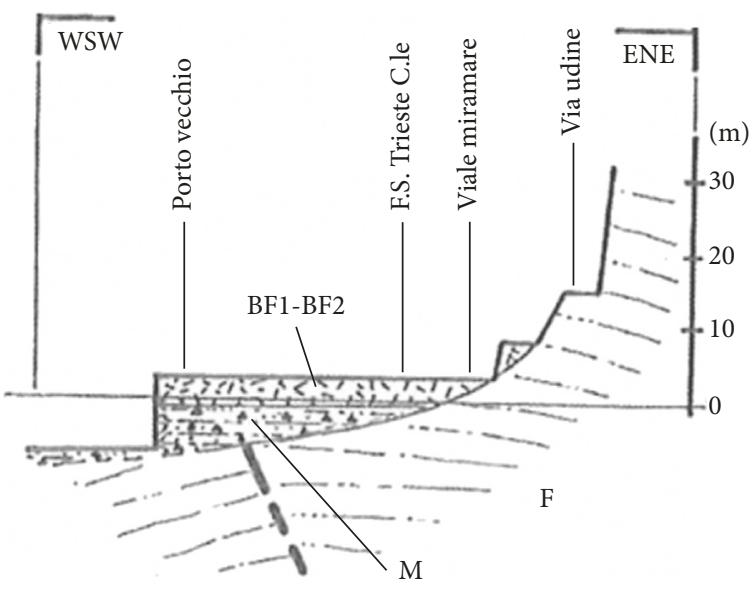

(a)

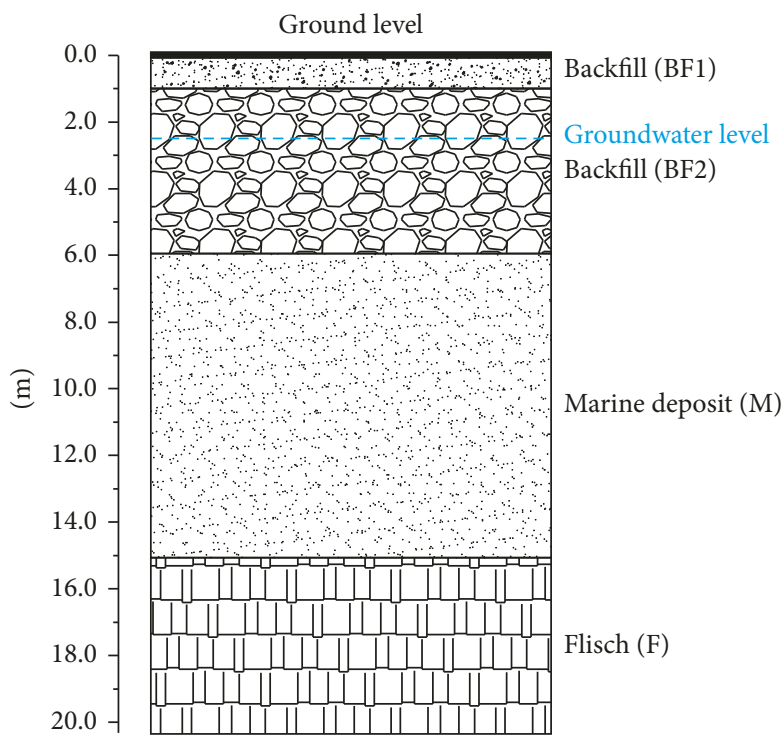

(b)

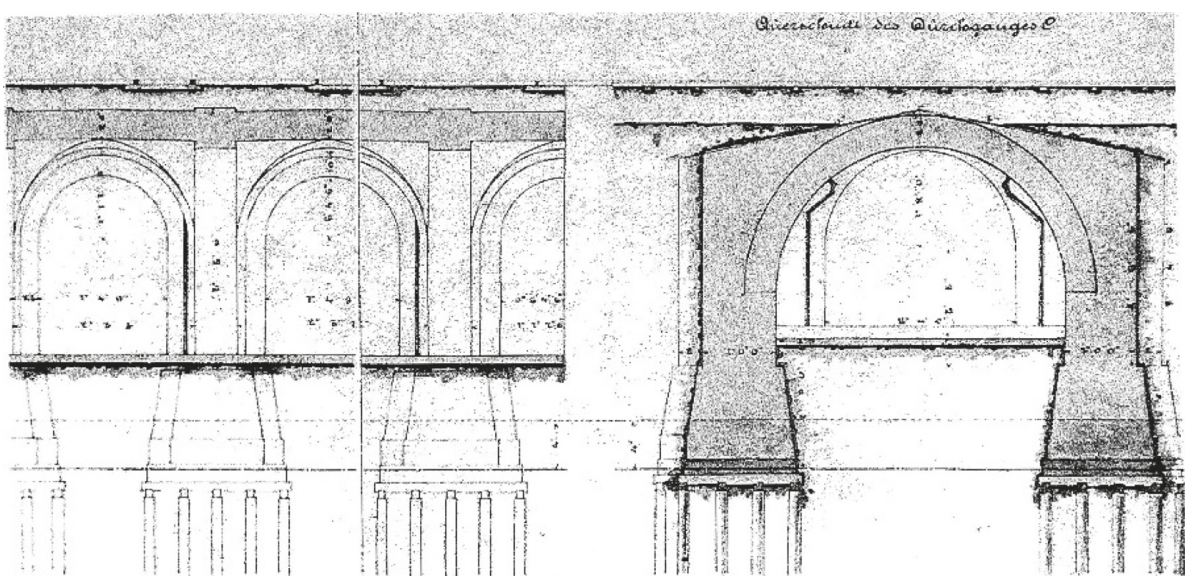

(c)

FIGURE 3: Geological characterization of the ground: (a) vertical section; (b) geotechnical interpretation of one of the probings executed; (c) the building foundations of the storehouses as depicted on the original 1850 drawings.

Geotechnical Engineering Laboratory of the University of Bologna. One smaller specimen was tested in situ (Figure 4(a)), while three specimens were extracted from perimeter walls and tested in the laboratory (Figures 4(b)-4(e)). Two more specimens were reconstructed in the laboratory using stones extracted from damaged walls and new mortar with composition similar to that found in situ. The in situ test on the wall specimen has been performed by means of 


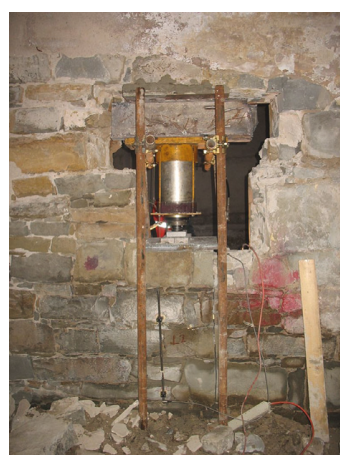

(a)

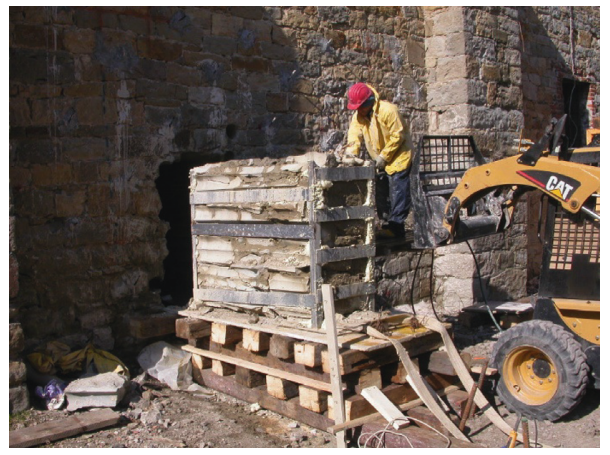

(c)
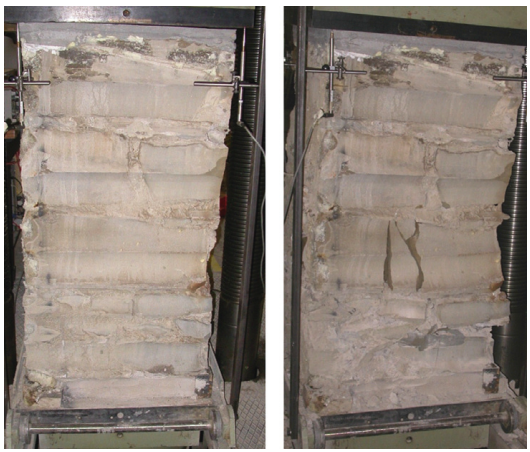

(e)

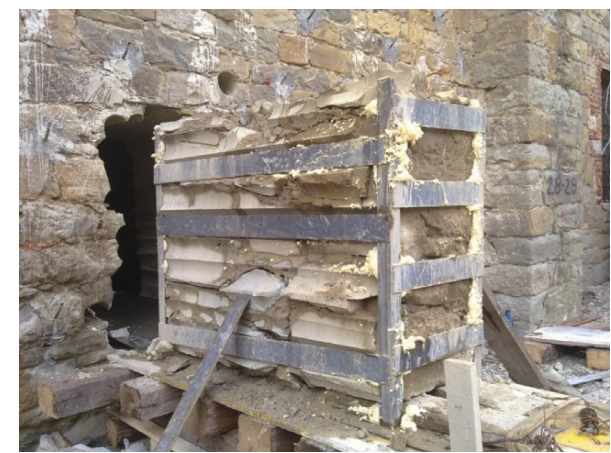

(b)

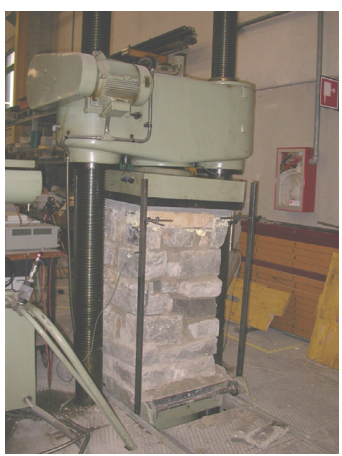

(d)

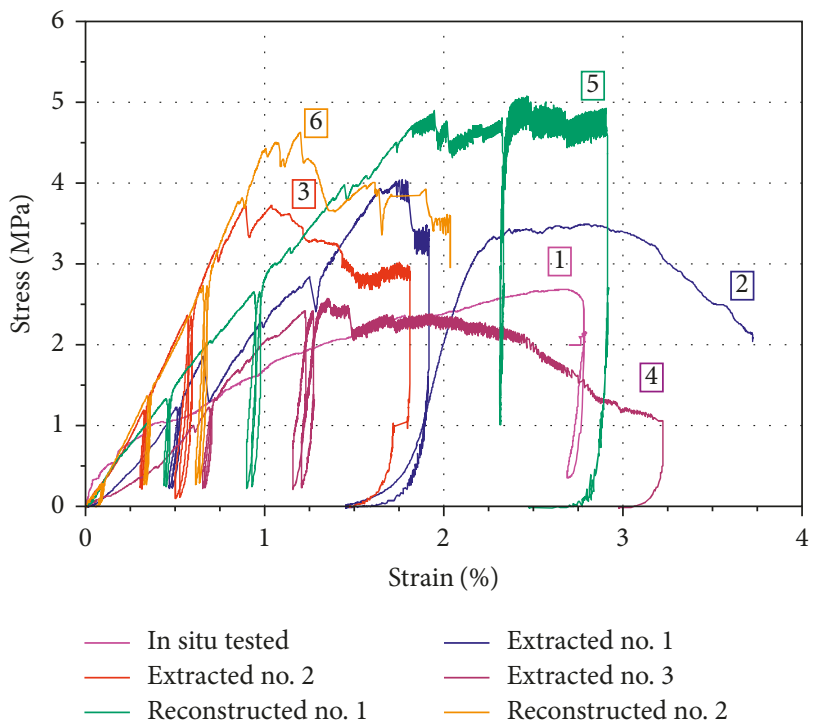

(f)

Figure 4: Compression tests on stonework specimens: (a) experimental setup for in situ compression test on specimen no. 1; (b) extraction of wall specimens; (c) transportation to the laboratory for testing; (d) experimental setup for laboratory compression test; (e) specimen no. 4 before (left) and after (right) compression test; (f) experimental stress-strain curves obtained from the in situ tests and laboratory tests on extracted and reconstructed specimens.

a compression force assigned by a hydraulic jack until the crushing of the panel. Between the hydraulic jack and wall specimen was inserted a thick steel plate so to transmit a more uniform state of stress at the stonework panel, thanks to the plan surface of the steel plate. Instead, for the specimens tested in laboratory (both reconstructed and extracted), a plan surface for the application of a uniform state of stress on the stonework wall has been obtained by introducing a horizontal layer of high-strength mortar having thickness variable from 3 to $4 \mathrm{~cm}$. 
TABLE 1: ID core sample: identification code.

\begin{tabular}{|c|c|c|c|c|c|}
\hline ID core sample & $\varnothing(\mathrm{mm})$ & $H(\mathrm{~mm})$ & $\Gamma\left(\mathrm{kN} / \mathrm{m}^{3}\right)$ & $f_{\mathrm{cp}}(\mathrm{MPa})$ & $f_{\text {cp,average }} \pm$ st. dev. $(\mathrm{MPa})$ \\
\hline $1-1$ & 54.16 & 54.27 & 25.86 & 161.4 & \multirow{3}{*}{$158.1 \pm 2.8$} \\
\hline $1-2$ & 54.06 & 54.30 & 26.01 & 154.6 & \\
\hline $1-3$ & 54.40 & 54.18 & 25.68 & 158.3 & \\
\hline $2-1$ & 54.46 & 54.10 & 25.54 & 156.2 & \multirow{3}{*}{$160.2 \pm 4.3$} \\
\hline $2-2$ & 54.34 & 53.81 & 25.75 & 166.2 & \\
\hline $2-3$ & 54.19 & 54.19 & 25.67 & 158.2 & \\
\hline $3-1$ & 54.32 & 54.25 & 24.81 & 102.0 & \multirow{3}{*}{$94.4 \pm 5.5$} \\
\hline $3-2$ & 54.13 & 54.10 & 24.76 & 91.6 & \\
\hline $3-3$ & 54.12 & 53.88 & 24.74 & 89.5 & \\
\hline $4-1$ & 54.22 & 54.27 & 25.64 & 134.2 & \multirow{3}{*}{$137.2 \pm 7.3$} \\
\hline $4-2$ & 54.19 & 53.25 & 25.69 & 130.1 & \\
\hline $4-3$ & 54.24 & 53.63 & 25.46 & 147.3 & \\
\hline $5-1$ & 54.51 & 54.55 & 25.11 & 133.6 & \multirow{2}{*}{$152.8 \pm 19.2$} \\
\hline $5-2$ & 54.28 & 54.44 & 25.56 & 172.0 & \\
\hline
\end{tabular}

Ø: diameter; $H$ : height; $\gamma$ : density; $f_{\mathrm{cp}}$ : ultimate compression stress of stone core specimens.

TABLE 2: ID-type: identification code and class of the wall specimens.

\begin{tabular}{|c|c|c|c|c|c|c|c|}
\hline ID-type of specimen & $L(\mathrm{~mm})$ & $B(\mathrm{~mm})$ & $H(\mathrm{~mm})$ & $\Gamma\left(\mathrm{kN} / \mathrm{m}^{3}\right)$ & $P_{u}(\mathrm{kN})$ & $f_{\mathrm{cb}}(\mathrm{MPa})$ & $E(\mathrm{MPa})$ \\
\hline (1) In situ tested & 400 & 460 & 820 & - & 494 & 2.68 & 273 \\
\hline (2) Extracted no. 1 & 623 & 641 & 1105 & 24.18 & 1613 & 4.04 & 320 \\
\hline (3) Extracted no. 2 & 657 & 634 & 1330 & 24.12 & 1554 & 3.73 & 488 \\
\hline (4) Extracted no. 3 & 655 & 620 & 1225 & 25.33 & 1044 & 2.57 & 255 \\
\hline (5) Reconstructed no. 1 & 629 & 588 & 1165 & 26.49 & 1875 & 5.08 & 262 \\
\hline (6) Reconstructed no. 2 & 595 & 604 & 1209 & 25.41 & 1662 & 4.63 & 449 \\
\hline Average of in situ tested (1) & & & - & & & 2.68 & 273 \\
\hline Average of extracted (2-3-4) & & & - & & & 3.45 & 354 \\
\hline Average of reconstructed (5-6) & & & - & & & 4.86 & 356 \\
\hline St. dev. of extracted (2-3-4) & & & - & & & 0.63 & 98 \\
\hline St. dev. reconstructed (5-6) & & & - & & & 0.22 & 94 \\
\hline
\end{tabular}

$L \times B \times H$ : dimensions; $\gamma$ : density; $P_{u}$ : ultimate compression load; $f_{\mathrm{cb}}$ : ultimate compression stress; $E$ : elastic modulus of stonework of the specimens tested.

Some additional compression tests on small diameter cylindrical core samples obtained from stone blocks were also conducted. In that case, the planarity of the cross sections at the extremities of the specimen was achieved by means of a mechanical grinding procedure. The results of the test on core samples are reported in Table 1. The compression strength of the stones is very high, about 130$160 \mathrm{MPa}$, being constituted of siliceous sandstone. The compression test results on wall specimens are summarized in Table 2 and depicted in Figure 4(f). The value of Young's modulus $(E)$ reported in Table 2 for each specimen has been calculated as secant stiffness modulus for a stress level equal to $1 / 3$ of the maximum stress reach from that specimen. The small strength values obtained from compression tests on wall specimens (especially if compared with the very high compression strength of stone blocks) are mainly due to the highly irregular texture and the corresponding large thickness of mortar layers with limited mechanical strength, causing very high deformability of the masonry with very inhomogeneous stress distribution in the specimen. The high deformability of the masonry is confirmed by its very low elastic modulus (ranging from $255 \mathrm{MPa}$ to $488 \mathrm{MPa}$ ), even one order of magnitude smaller than that usually found in masonry.

The presence of irregular stress states is confirmed by the failure mode of the wall specimens, typically anticipated by the fracture under bending of some stone blocks subject to inhomogeneous settlements during the wall compression tests. The specimen reconstructed in laboratory showed analogous deformability but compression strength about $20 \%$ greater, due to the more controlled conditions of realization.

4.2. Tests on Foundations. For a correct interpretation of the structural behavior of the buildings, an important role is played by the foundation elements. This aspect was particularly significant for the structure at hand, because the new architectural design proposes the reuse of the building 


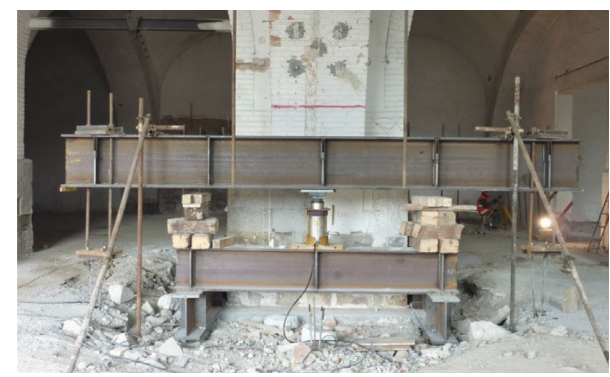

Figure 5: Loading system realized for the tests on foundation plinths.

as a shopping centre, after consolidation interventions, with an increase of dead and live loads of about $30 \%$ with respect to the actual loading levels.

In order to estimate the load-carrying capacity and vertical settlement of the foundation system, four typical plinths (indicated with a blue color in Figure 2(a)) were tested with an increasing static vertical load. The loading system was composed of a double metallic frame, the lower one transferring the load to the plinths and the upper one providing for the reaction system by means of four steel wire ropes anchored to the ground. The load was then applied by two hydraulic jackets placed between the two frames (Figure 5). For each test, the vertical displacements of four points on the pillar faces were measured by means of two optical levels with 0.01 millimeters of sensitivity, and the mean vertical displacement of the pillar was calculated as the mean value of the four displacements.

The force-displacement curves obtained for each of the four tested plinths are reported in Figure 6(a). The maximum applied force corresponds to the loading increase estimated by the designers. For each step, the loading was kept constant for 15-20 minutes. The maximum loading was reached after 2-4 hours of test and then kept constant for 14-16 hours before unloading (Figure 6(b)).

Looking at the general trend of the four graphs, the behavior of the soil-foundation system seems to be nonlinear even for low levels of applied force, but values of the vertical displacements of the foundation remain very limited even at the maximum loading level. The loads were increased very slowly during the test in order to allow the dissipation of pore water pressure in the soil and to include possible viscous soil deformation (Figure 6(c)). It is interesting to remark that, at the maximum loading level, the foundation exhibited most of the viscous displacements (varying from 25 to $60 \%$ of the instantaneous displacements). Furthermore, after the complete loading removal, a significant permanent displacement of the foundations was recorded.

A preliminary interpretation of the results and a correlation with size, stiffness, and effectiveness of the existing wooden piles-pad footing foundation system could be obtained by looking at the ancient drawings of the storehouse. The original sketches of the foundations (Figure 3(c)), dated back to 1850, show a series of fir-tree piles embedded in the ground under the stone pad footing and bearing the structures above the columns (as shown in Figure 7(a)).

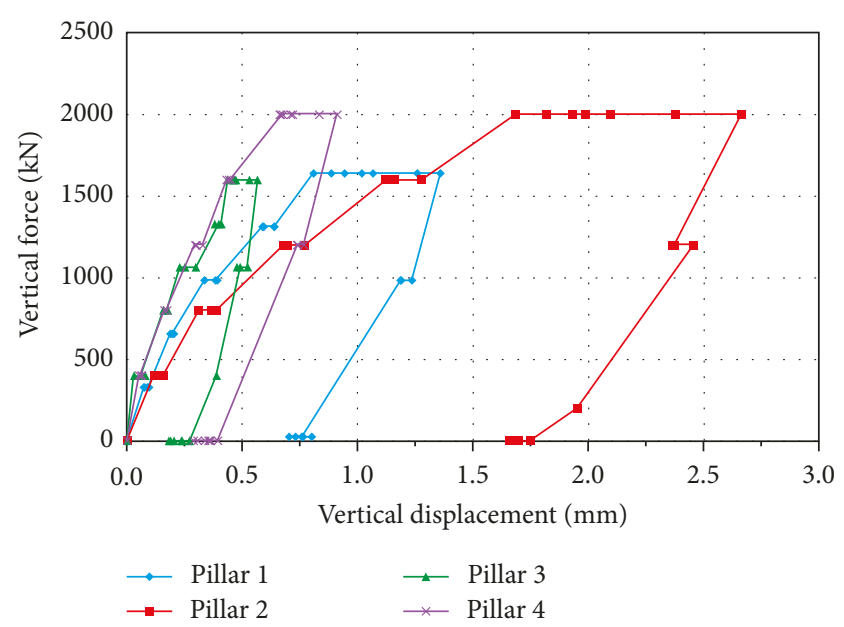

(a)

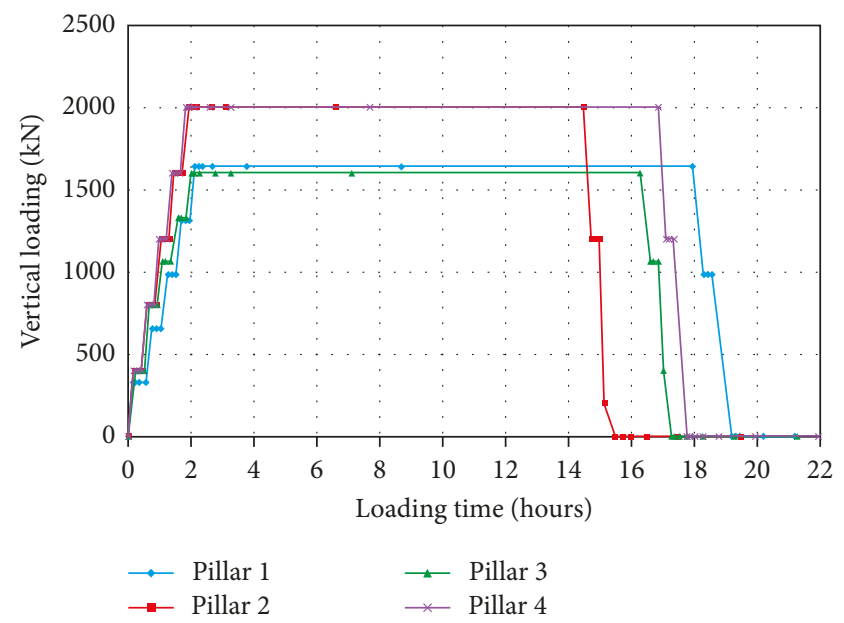

(b)

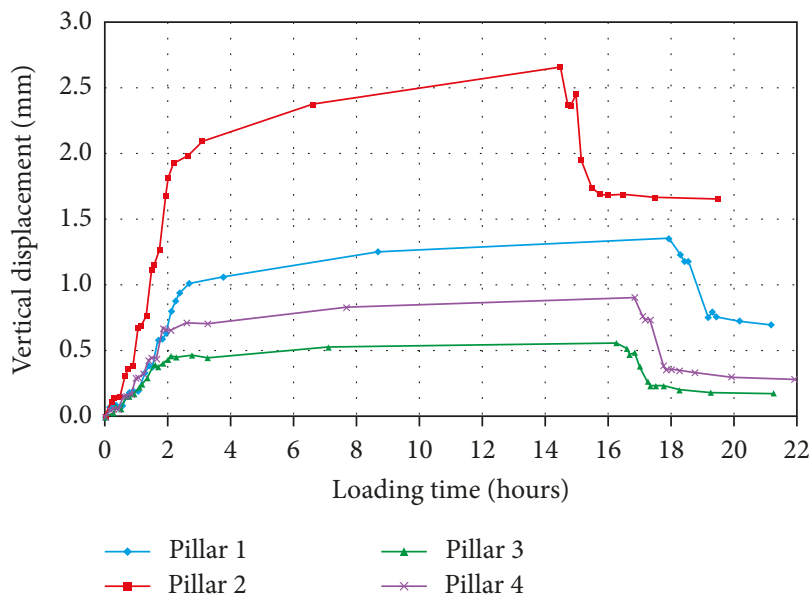

(c)

FIGURE 6: Experimental results on pillar foundations plinths: (a) vertical force versus vertical displacement curves; (b) vertical loading versus time; (c) vertical displacement versus loading time.

Under the pad footing, there is a system of five-by-five piles, characterized by spacing $s=80-90 \mathrm{~cm}$ and diameter $d=30-35 \mathrm{~cm}$. The shape of the pad footing is rectangular with dimensions of $3.80 \times 4.10 \mathrm{~m}^{2}$. 


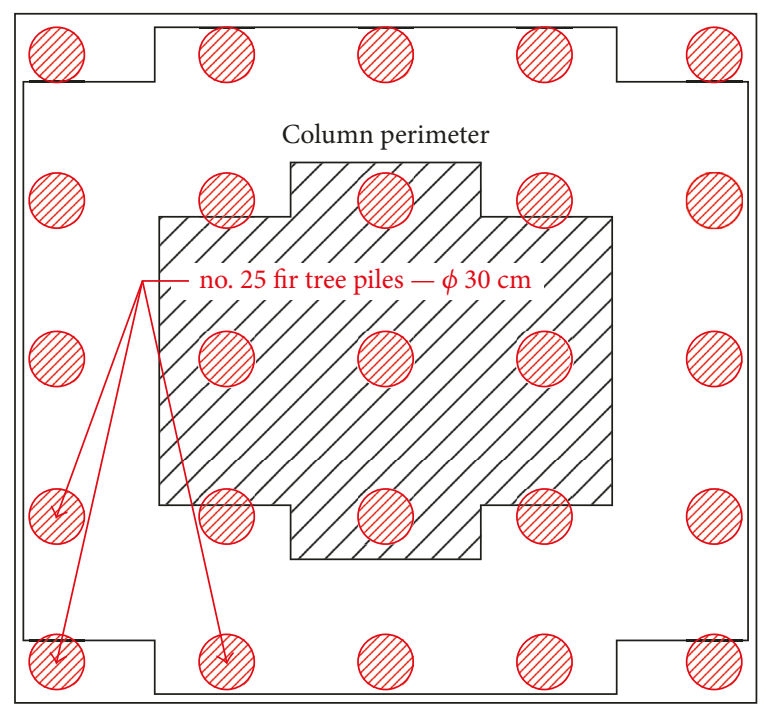

Foundation base perimeter

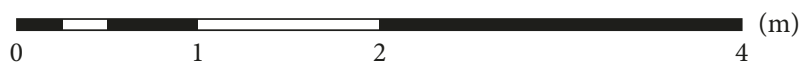

(a)
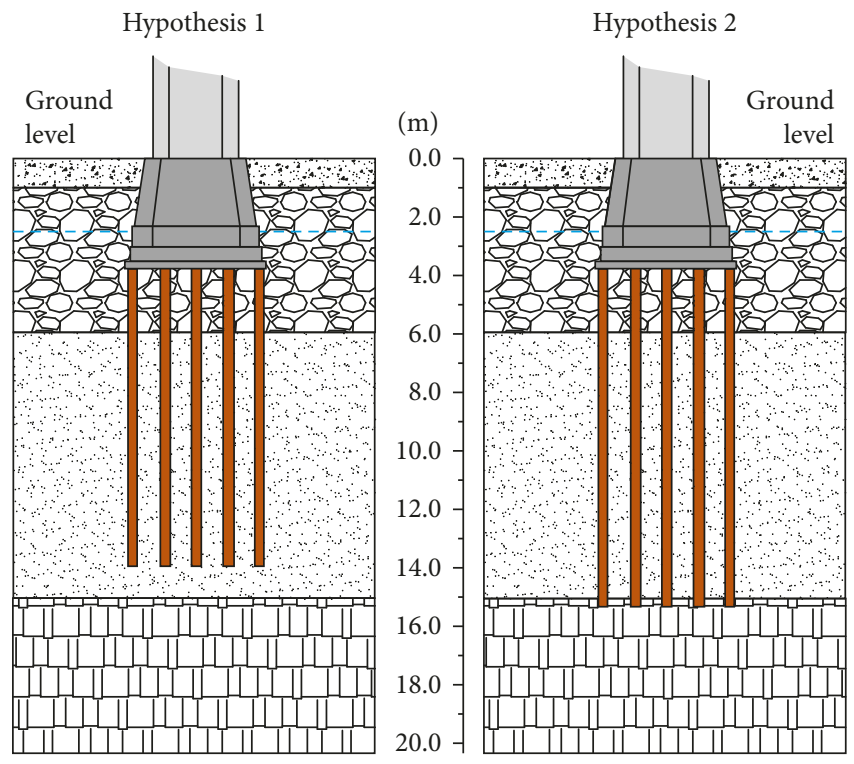

(b)

FIGURE 7: Wooden piles-pad footing foundation system: (a) plan of a typical column foundation with the piles position; (b) two different hypotheses about the pile length leading to floating piles (hypothesis 1) and end-bearing piles (hypothesis 2) conditions.

No information is available with regard to the piles length $(L)$. Typically, the driven wooden piles have a 10-15meter length [21] and, with reference to the driving systems used in the nineteenth century, the piles could hardly be driven inside the bedrock, which is actually about $15 \mathrm{~m}$ below the ground level. Thereby, with reference to the soil stratigraphy obtained from the geotechnical survey performed in the neighborhoods of the building (Figure 3(b)), two different hypotheses were made on the piles length, as shown in Figure 7(b). In the first case, piles have a $10 \mathrm{~m}$ length and do not reach the hard Flash layer (floating piles); in the second case, the piles length is $11 \mathrm{~m}$, and they reach the hard soil (end-bearing piles). The verification of the most realistic hypothesis was performed by using, as a reference, the experimental results obtained from the in situ test on foundation of pillar no. 4, identified as the most typical among the various tested.

In order to evaluate the stiffness of the foundation system, an analytical model of piles embedded in the soil, based on elastic behavior, was considered. In more detail, the settlement of the top of a pile subject to vertical loading may be expressed in terms of the settlement of an incompressible single pile embedded in a half-space, properly adjusted by means of some correction factors. In the case of a floating pile (hypothesis 1), the settlement $\rho$ can be estimated according to the expression furnished in Poulos and Davis [21] as

$$
\rho=\frac{P I}{E_{S} d}
$$

where $\rho=$ settlement of pile head; $P=$ axial load on pile; $E_{S}=$ Young's modulus of the soil (assumed as uniform around the pile); $d=$ diameter of pile; $I=I_{0} \cdot R_{k} \cdot R_{h} \cdot R_{v}$, with $I_{0}$ being influence factor for incompressible pile in a semiinfinite medium with $v_{s}=0.5, R_{k}$ the correction factor for pile compressibility, $R_{h}$ the correction factor for finite depth of compressible layer on a rigid base, and $R_{v}$ the correction factor for soil Poisson's ratio $v_{s}$ smaller than 0.5.

Considering the pile length as $L=10 \mathrm{~m}$ and its diameter as $d=0.3 \mathrm{~m}$, the pile aspect ratio $L / d$ (length/diameter) is 33.3. From the graphs reported in Poulos and Davis [21] and assuming coherently $v_{s}=0.45, K=1000$, and $h=11 \mathrm{~m}$ (with $v_{s}$ the Poisson ratio of the soil, $K$ the pile-stiffness correction factor, and $h$ the thickness of the compressible soil layer under the pad-footing base), the values of $I_{0}=0.065, R_{k}=1.15$, $R_{h}=0.4$, and $R_{v}=0.98$ are obtained, leading to $I=0.0293$.

Since under the pad footing there was a group of piles, the reciprocal interaction effect has to be considered and, consequently, the vertical settlement $\rho_{g}$ of a group of piles can be obtained as

$$
\rho_{g}=R_{s} P_{\mathrm{av}} \rho_{1}=R_{s} P_{\mathrm{av}} \frac{I}{E_{S} d},
$$

with $R_{s}=$ average group settlement divided by the settlement of a single pile subject to the same average load, $P_{\mathrm{av}}=$ average load on a pile belonging to a group of piles, and $\rho_{1}=$ displacement of a single pile under unit load with $P=1$ (see (1)).

Considering the elastic modulus of the soil $E_{s}=20 \mathrm{MPa}$ (average value obtained from the geotechnical survey results) and $R_{s}=8.30$ (obtained from Table 6.2 in Poulos and Davis [21] for the present geometry and mechanical properties of the materials), the expected group settlement can be evaluated. In particular, this settlement was evaluated for a vertical load of $2000 \mathrm{kN}$, common also to test performed on foundation of pillar no. 4 (Figures 1 (a) and 2), and leading to a value $\rho_{g}=3.24 \mathrm{~mm}$ in the case of floating piles (hypothesis no. 1).

Considering an end-bearing group of piles instead (hypothesis no. 2), the aspect ratio becomes $L / d=36.7$, and 
the vertical settlement is given by (1) with the parameter $I$ equal to

$$
I=I_{0} R_{k} R_{b} R_{v},
$$

where $I_{0}, R_{k}$, and $R_{v}$ are as mentioned earlier and $R_{b}$ (base modulus correction factor for the presence of a stiff-bearing stratum) can be evaluated from the ratio $E_{b} / E_{s}$, where $E_{b}$ is the Young modulus of the base layer. Assuming $E_{b}=2000 \mathrm{MPa}, R_{b}$ becomes 0.35 , while $I=0.0256, R_{s}=2.12$ can be obtained from Poulos and Davis [21]. Hence, the vertical settlement $\rho_{g}=0.72 \mathrm{~mm}$ under vertical loading of $2000 \mathrm{kN}$ is attained. Comparison between settlements evaluated according to the two different hypotheses and the measured ones, equal to $0.68 \mathrm{~mm}$ (see graph of pillar no. 4 in Figure 6(a)), suggests that hypothesis 2 (end-bearing piles) would be the more realistic one.

\subsection{Tests on Arches}

4.3.1. Static Tests. The principal elements bearing the vertical loads are the perimeter walls and the intermediate pillars, connected by a series of transverse and longitudinal arches. An important expected outcome of the experimental campaign was the relative stiffness of transverse and longitudinal arches, required to assess how they carry out the vertical loads of the first floor as well as the transmission mechanism of the horizontal forces due to earthquake excitation.

Three different types of tests were performed on four representative transverse arches of the buildings, indicated in Figure 2(a): a static test with symmetric vertical load, a static test with asymmetric vertical load, and a series of dynamic tests with weight release. The symmetric static tests consisted in the application of two increasing forces at the quarters of the arch, while in asymmetric tests the load was applied to one quarter only. A properly designed steel reaction system allowed performing the static load tests by pulling the arches from below by means of steel wire ropes anchored in the ground (Figure 8).

During the static load tests, vertical and horizontal displacements of representative points of the arches were recorded. The instrument position during static tests is shown in Figures 8(a) and 8(b). A wild optical level with 0.01 millimeters of sensitivity was used in order to measure the arch vertical deflection in positions indicated by L1-L5. A wire displacement transducer (T1) was used in order to confirm the outcomes of midspan deflection from the optical level measures. Six additional displacement inductive transducers (linear variable differential transformer (LVDT)) with 0.001 millimeters sensitivity were used to measure the horizontal displacements of points at the wall-arch connection line (LVDT7 and LVDT8) and to obtain mean strains at the key brick position (LVDT3 and LVDT4).

The results obtained from all arches subject to in situ tests are compared in the following. The vertical displacements measured during symmetric static loading tests for different symmetrical loading steps $(150 \mathrm{kN}, 200 \mathrm{kN}, 250 \mathrm{kN}$, and $350 \mathrm{kN}$ ) are reported in Figures 9(a)-9(d). As expected, an approximately symmetrical behavior is observed with vertical displacements of midspan regularly increasing with the applied loading. The maximum recorded vertical displacement was $2.10 \mathrm{~mm}$, for arch no. 3 at the maximum applied load. The vertical displacements obtained at midspan by means of the optical instrument (dashed line in Figure 9(e)) matched well with those obtained with the wire transducer (solid line in Figure 9(e)). For each loading step, the load was maintained constant for 15 minutes and for 30 minutes at the maximum loading. The residual displacements after unloading reached a midspan value of $0.33 \mathrm{~mm}$, $0.03 \mathrm{~mm}, 0.63 \mathrm{~mm}$, and $0.25 \mathrm{~mm}$ (equivalent to $29 \%, 28 \%$, $30 \%$, and $15 \%$ of the maximum values obtained during loading), respectively, for arch no. 1 to no. 4 .

Figures 10(a) and 10(b) show the evolution of horizontal mean strain at the key brick position (calculated from LVDT3 and LVDT4 measures at the two sides of the arch) and the vertical average strain in the upper small wall belonging to the arch and originally supporting the wood deck, calculated from LVDT5-6 displacements at the quarters, just below the vertical loading application. As far as the arches subject to asymmetric static loadings are concerned, vertical displacements are reported in Figures 11(a)-11(c). Also in this case, the maximum value of the vertical displacement was obtained for arch no. 3, equal to $1.97 \mathrm{~cm}$ under the maximum applied load of $350 \mathrm{kN}$.

Different arches showed similar results under symmetric loading, their deflections being comparable and very similar. A slightly nonlinear behavior can be observed for higher levels of load, with vertical displacements no longer proportional to the applied loading. Under asymmetric loading condition, the results have similar trends but with significantly different values. It was expected, since the four tested arches showed different and quite heterogeneous deterioration conditions and different "boundary" situations, especially in terms of type of upper floor, perimeter walls, and internal partitions affecting the overall mechanicalstructural behavior.

4.3.2. Dynamic Vibration Tests. Dynamic load tests were also carried out, in order to evaluate the natural vibration frequencies of arches. A $2.5 \mathrm{kN}$ dead weight was hung at the arch intrados, by means of a harmonic metal wire, at the quarter of the span position so as to excite also nonsymmetric vibration modes. Then, the weight was instantaneously released, and the accelerations recorded immediately after the load release, in selected positions of arch, were recorded using three piezoelectric accelerometers. The accelerometer positions are indicated as A6-A8 in Figure 8. By postprocessing the acceleration recording, the power spectral density of the signals was computed in order to estimate the natural vibration frequencies. The first and the second natural frequencies identified for each of the four arches are reported in Table 3. It is important to remark that vertical frequencies identified belong to a range typical of modern structures, confirming the high stiffness of bearing structures necessary to avoid excessive deformability and vibration problems for the 


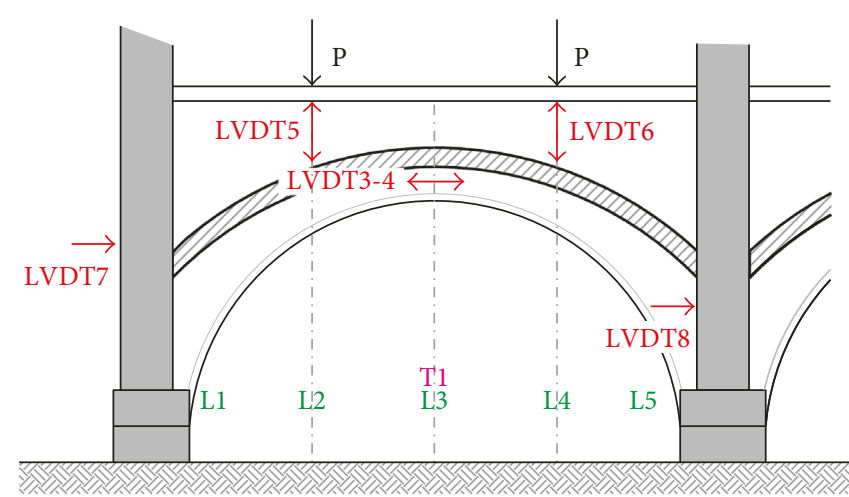

(a)

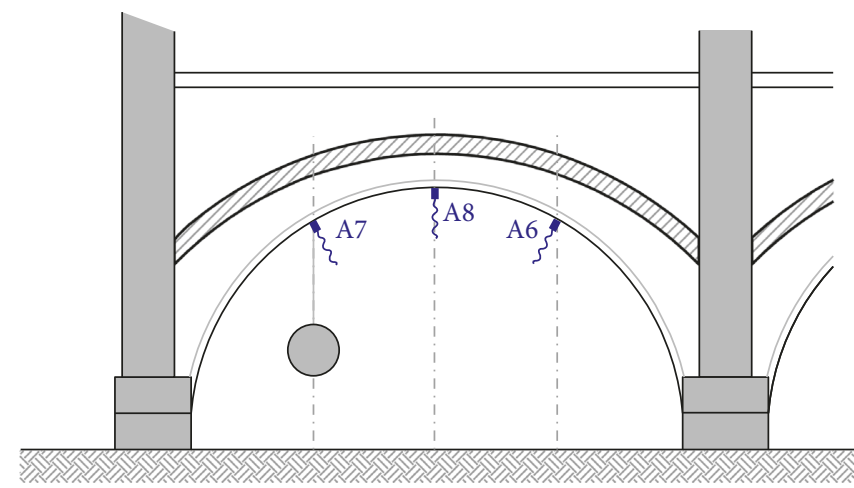

(c)

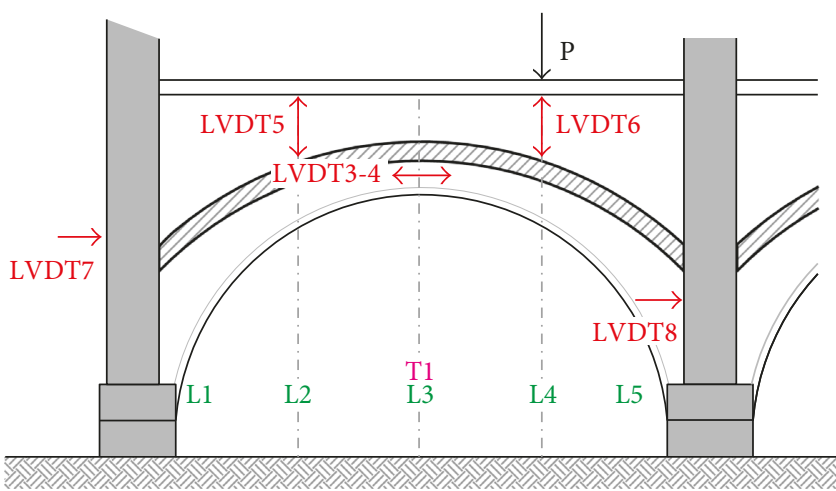

(b)

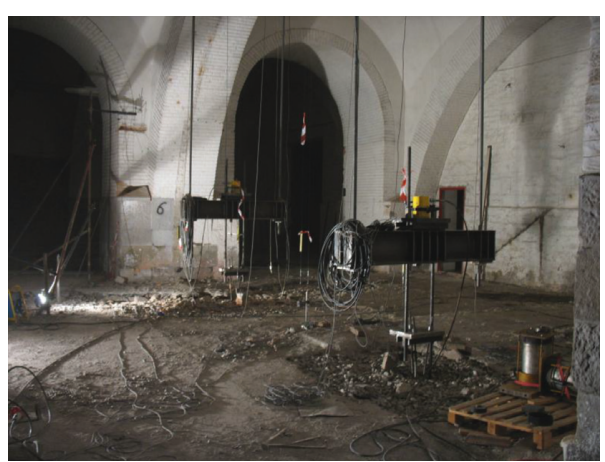

(d)

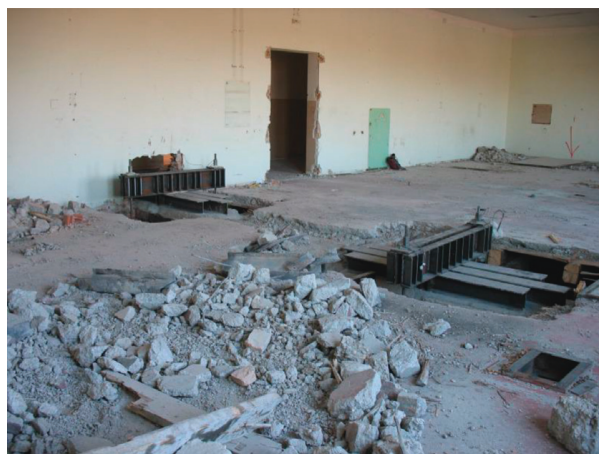

(e)

FIGURE 8: Tests on transverse arches. Instruments adopted during (a) static symmetrical test; (b) static asymmetrical test; (c) dynamic test with weight release; (d) details of the steel frame system adopted for the application of the static load; (e) connection of the system to the arch.

loading conditions expected in future for the new intended use. Anyway, resonant problems at the vaulted floor elements, due to walking people, can be reasonably excluded because of the high values of the vertical frequencies of the structural system.

\section{Conclusions}

This paper presents the main procedure adopted in the knowledge process of a large monumental nineteenth century building designed and used for many years as storehouses and recently inserted in a conservation project with possible transformation in auditorium and urban facilities.

The results of both the historical research and building survey were collected and analyzed as the preliminary step before the experimental campaign.

The authors, considering an alternative and not conventional investigation approach, preferred a limited number of experimental NDTs on full-scale typological systems instead of a more typical approach requiring a higher number of local measures coming from DTs on specimens of the different materials. In this way, it has been possible to capture the global behavior of the subsystems (i.e., transverse main 

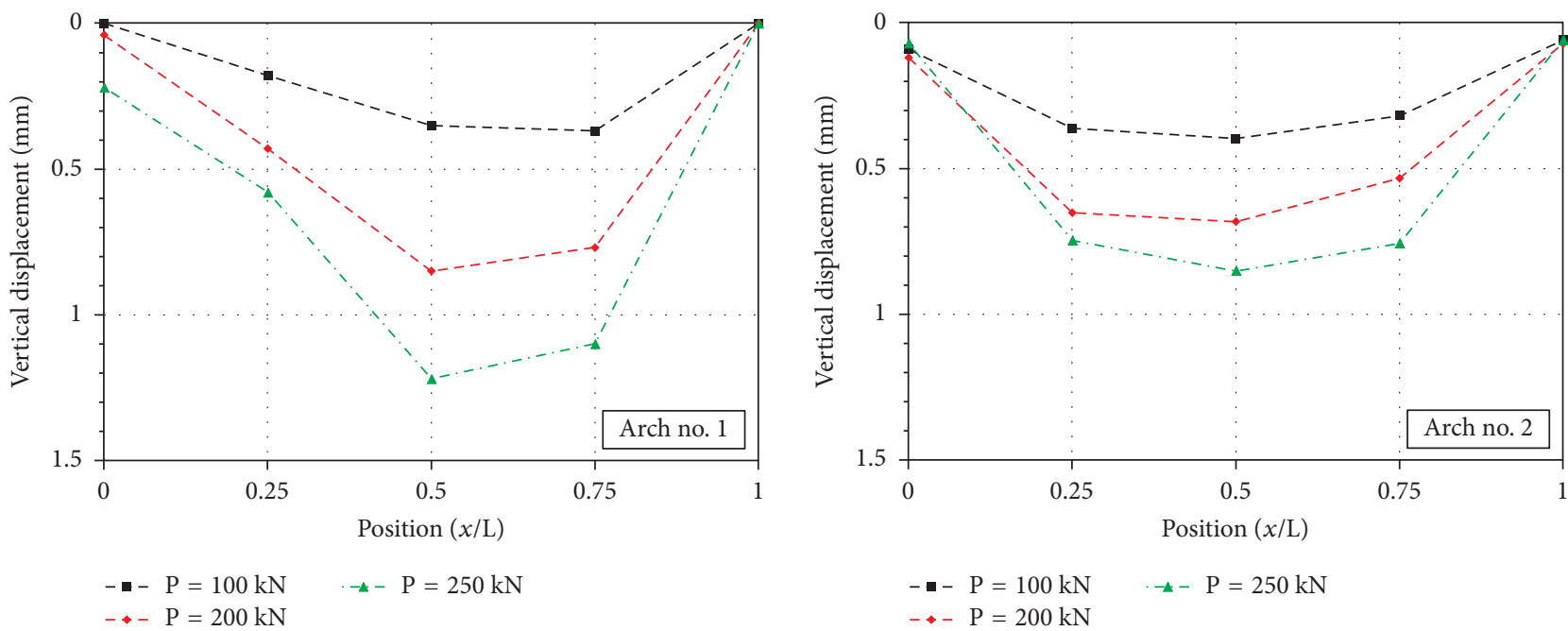

(a)

(b)

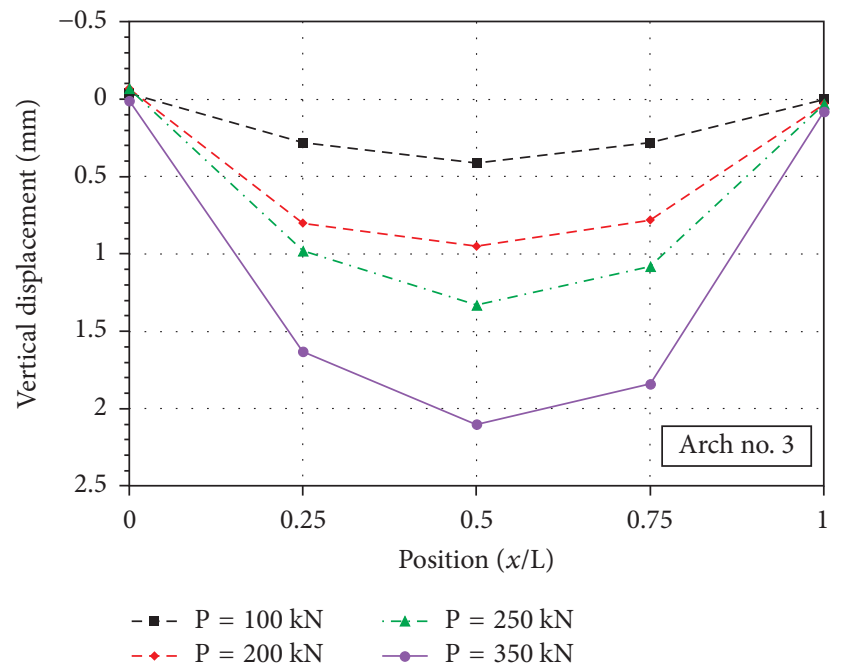

(c)

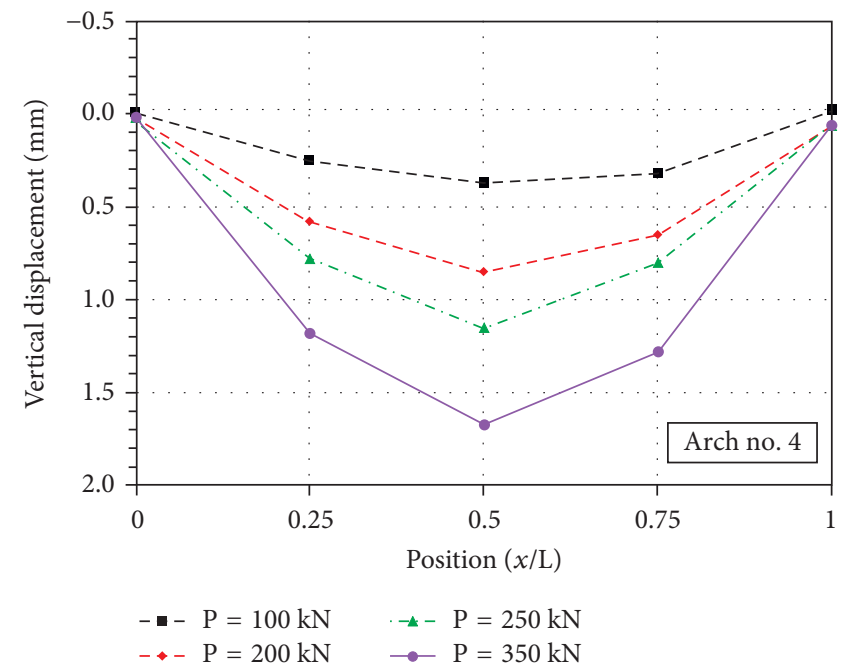

(d)

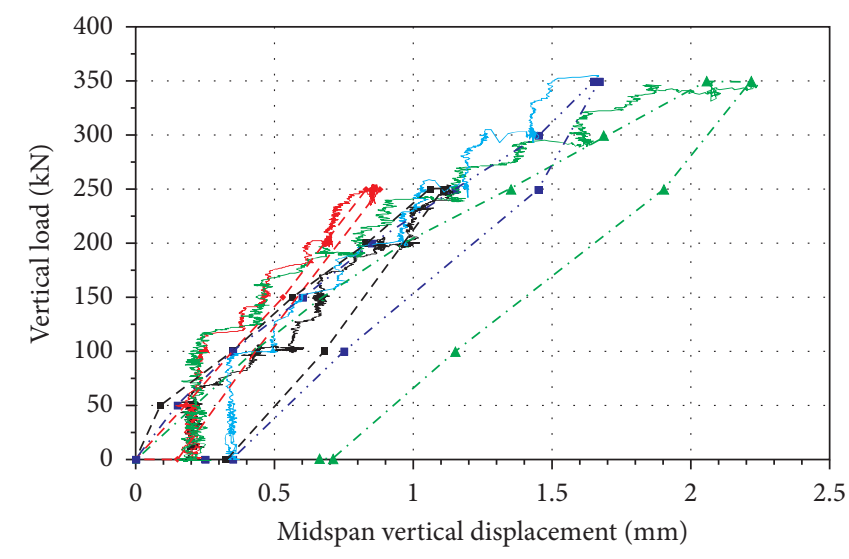

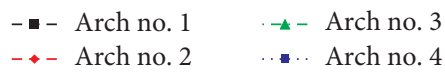

(e)

Figure 9: Test on arches subject to static symmetric loading: (a)-(d) vertical displacements obtained by optical level; (e) comparison of displacements at midspan. 


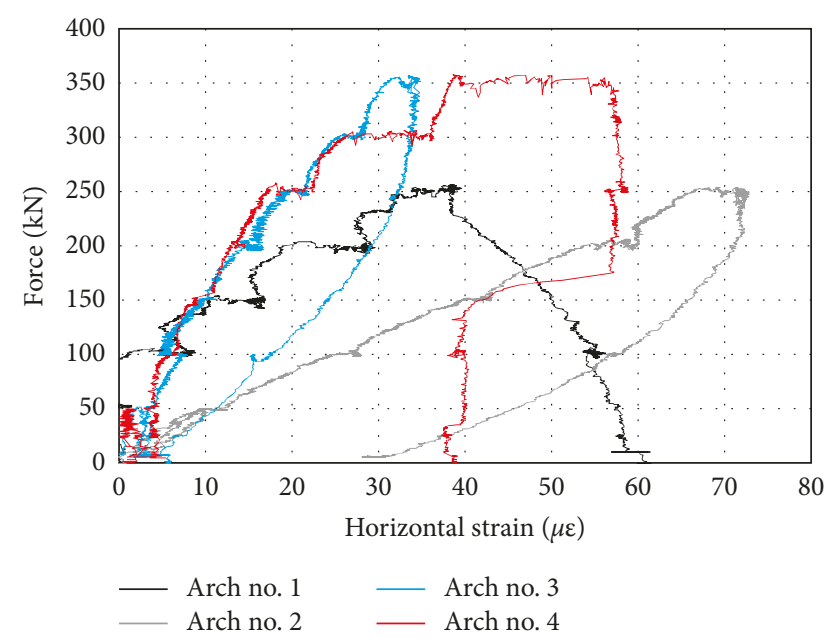

(a)

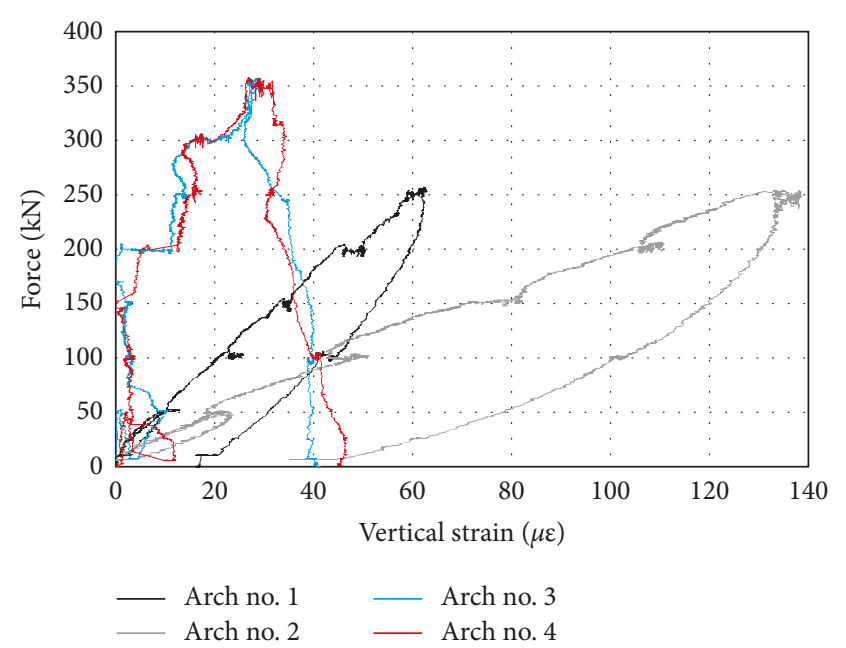

(b)

Figure 10: Test on arches subject to static symmetric loading (Figure 8(a)): (a) horizontal average strain measured at key brick; (b) vertical average strain measured at the quarters on the upper wall portion on the arch.

arches, perimeter walls, central longitudinal arches, and vaulted floor) that constitute the wings of the storehouses, but considering a very limited number of DTs.

The choice of the type of tests to be carried out comes from the need of being not too invasive, on one side, and of obtaining quantitative information on the state of preservation of the materials, on the other one. As a result, a mix of DT and NDT was carried out. The former dedicated to the local investigation of the masonry mechanical performances and the latter to the behavior and collaboration of the different structural elements; this was particularly relevant for the strongly statically redundant vaulted elements. The results of in situ and laboratory tests are presented and discussed in this paper. The experimental tests carried out on wall specimens allowed to estimate the compressive strength of the very thick perimeter walls. Tests on foundations and stone arches were performed to estimate, respectively, the expected settlements of the ground and the deflections and

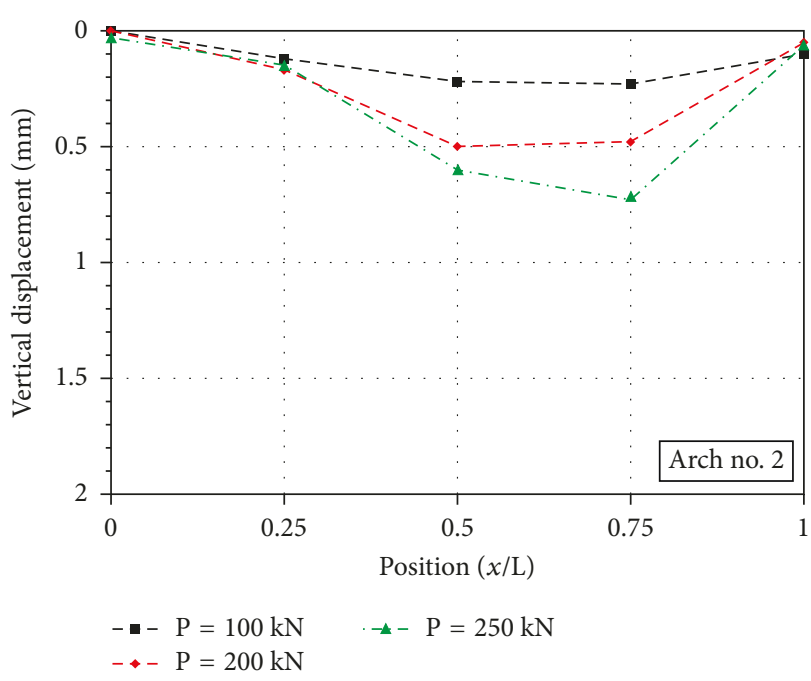

(a)

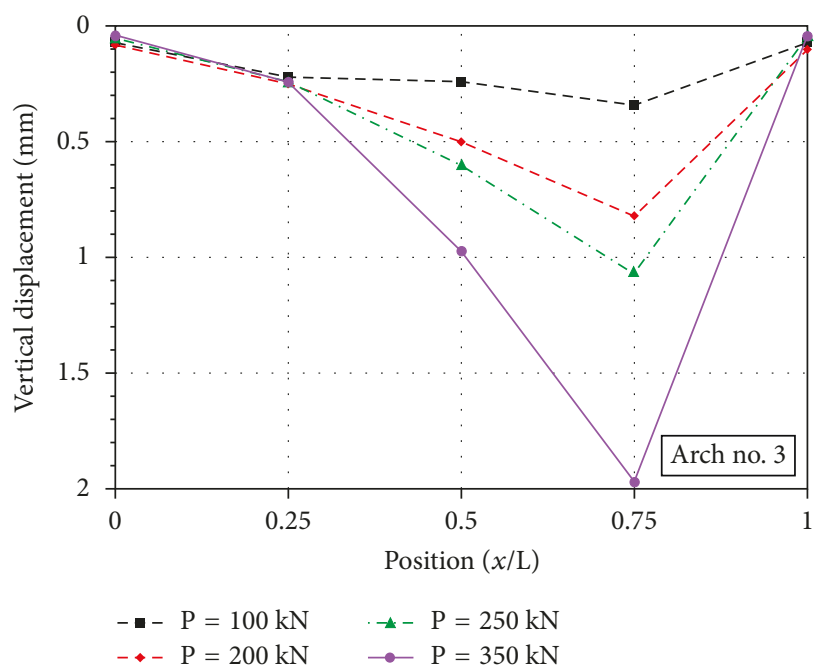

(b)

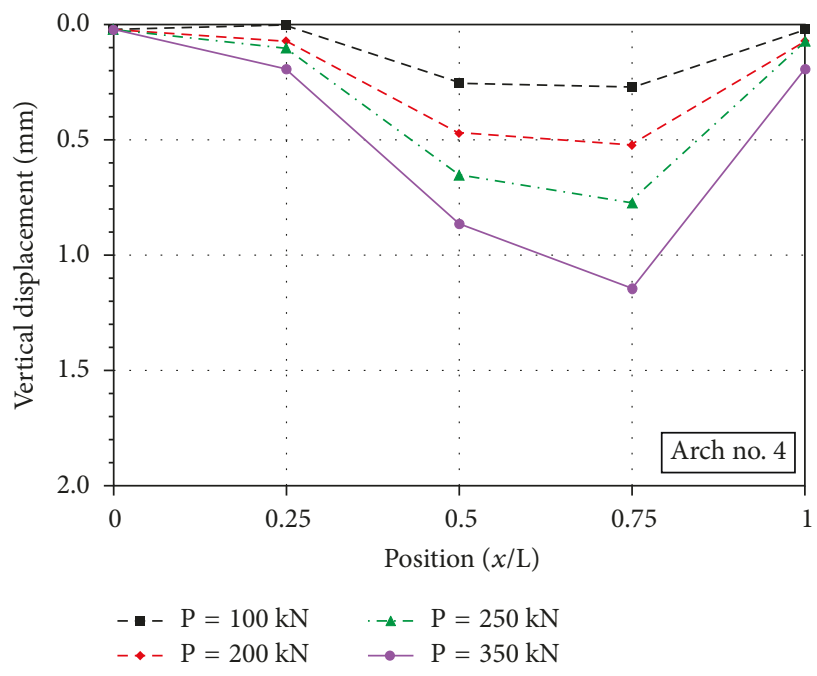

(c)

FIgURE 11: Test on arches subject to static asymmetric loading: (a)-(c) vertical displacements obtained by optical level for the three arches tested. 
TABLE 3: First two natural frequencies obtained from dynamic in situ tests on arches.

\begin{tabular}{lcc}
\hline Arch no. & $f_{1}(\mathrm{~Hz})$ & $f_{2}(\mathrm{~Hz})$ \\
\hline 1 & 9.0 & 15.8 \\
2 & 15.6 & 19.5 \\
3 & 12.1 & 17.9 \\
4 & 15.0 & 18.6 \\
\hline
\end{tabular}

the degree of collaboration of the bearing structure system, constituted by walls, arches, and vaults, and due to the increase of vertical loading level. From the experimental tests, very useful information on the structural response has been obtained, and the outcomes allowed to properly define the numerical finite element models to adopt for the design of restoration interventions required from the loading of the new intended use of the complex.

\section{Conflicts of Interest}

The authors declare that there are no conflicts of interest regarding the publication of this paper.

\section{References}

[1] D. D'Ayala and E. Speranza, "Definition of collapse mechanisms and seismic vulnerability of masonry structures," Earthquake Spectra, vol. 19, no. 3, pp. 479-509, 2003.

[2] V. Mallardo, R. Malvezzi, E. Milani, and G. Milani, "Seismic vulnerability of historical masonry buildings: a case study in Ferrara," Engineering Structures, vol. 30, no. 8, pp. 2223-2241, 2008.

[3] J. Azevedo, G. Sincraian, and J. V. Lemos, "Seismic behavior of blocky masonry structures," Earthquake Spectra, vol. 16, no. 2, pp. 337-365, 2000.

[4] M. Tomaževic and P. Weiss, "A rational, experimentally based method for the verification of earthquake resistance of masonry buildings," in Proceedings of the Fourth U.S. National Conference on Earthquake Engineering, vol. 2, pp. 349-359, Palm Springs, CA, USA, May 1990.

[5] G. M. Calvi, G. R. Kingsley, M. Eeri, and G. Magenes, "Testing of masonry structures for seismic assessment," Earthquake Spectra, vol. 12, no. 1, pp. 145-162, 1996.

[6] P. Ortiz, V. Antunez, J. M. Martin, R. Ortiz, M. A. Vázquez, and E. Galan, "Approach to environmental risk analysis for the main monuments in a historical city," Journal of Cultural Heritage, vol. 15, no. 4, pp. 432-440, 2014.

[7] S. Chiostrini, L. Galano, A. Vignoli, D. R. Petersen, and R. E. Link, "In situ shear and compression tests in ancient stone masonry walls of Tuscany, Italy," Journal of Testing and Evaluation, vol. 31, no. 4, pp. 289-304, 2003.

[8] A. Baratta, I. Corbi, O. Corbi, and D. Rinaldis, "Experimental survey on seismic response of masonry models," in Proceedings of 6th International Conference Structural Analysis of Historical Constructions Preservation, Bath, UK, July 2008.

[9] L. Binda, A. Saisi, and C. Tiraboschi, "Investigation procedures for the diagnosis of historic masonries," Construction and Building Materials, vol. 14, no. 4, pp. 199-233, 2000.

[10] R. Hayen, K. Van Balen, and D. Van Gemert, "Triaxial interaction of natural stone, brick and mortar in masonry constructions," in Proceedings of 1st WTA International PhD Symposium, Leuven, Belgium, 2009.
[11] A. J. Francis, C. B. Horman, and L. E. Jerrems, "The effect of joint thickness and other factors on compressive strength of brickwork," in Proceedings of 2nd International Brick Masonry Conference, pp. 31-37, Stoke, Kent, UK, 1971.

[12] C. Conte, C. Rainieri, M. A. Aiello, and G. Fabbrocino, "Onsite assessment of masonry vaults: dynamic tests and numerical analysis," Geofizika, vol. 28, no. 1, pp. 127-143, 2011.

[13] P. F. Sheppard, "In-situ test of the shear strength and deformability of an 18th century stone and brick masonry wall," in Proceedings of 7th International Brick and Block Masonry Conference, vol. 1, pp. 149-160, Melbourne, Australia, February 1985.

[14] R. Aguilar, R. Marques, K. Sovero, C. Martel, F. Trujillano, and R. Boroschek, "Investigations on the structural behaviour of archaeological heritage in Peru: from survey to seismic assessment," Engineering Structures, vol. 95, pp. 94-111, 2015.

[15] A. De Luca, A. Giordano, and E. Mele, "A simplified procedure for assessing the seismic capacity of masonry arches," Engineering Structures, vol. 26, no. 13, pp. 1915-1929, 2004.

[16] K. Kirtschig, "On the failure mechanism of masonry subject to compression," in Proceedings of 7th International Brick and Block Masonry Conference, vol. 1, pp. 625-629, Melbourne, Australia, 1985.

[17] M. Savoia and R. Carli, "L'utilizzo di tecniche di indagine soniche per la valutazione dell'efficacia dei consolidamenti nelle murature storiche," in Proceedings of 18th Career Technical Education Congress, Brescia, Italy, 2010.

[18] J. G. M. Creemers and R. K. W. M. Klaassen, "Wooden foundation piles and its underestimated relevance for cultural heritage," Journal of Cultural Heritage, vol. 13, no. 3, pp. S123-S128, 2012.

[19] G. Abrami, "Decay in wooden foundations, the Italian situation," in Final report EU project EVK4-CT-2001-00043: Preserving Cultural Heritage by Preventing Bacterial Decay of Wood in Foundation Piles and Archaeological Sites Chapter 2, R. K. W. M. Klaassen, Ed., pp. 34-45, Wageningen, Netherlands, 2005.

[20] Geolitological Chart, Regione Autonoma Friuli-Venezia Giulia-Comune di Trieste-Personal Communication, 2009.

[21] H. G. Poulos and E. H. Davis, Pile Foundation Analysis and Design, John Wiley, New York, NY, USA, 1980. 


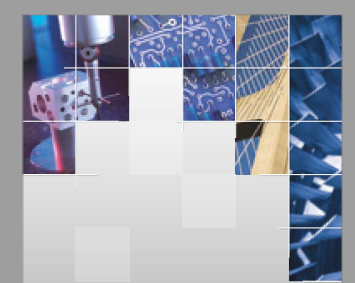

\section{Enfincering}
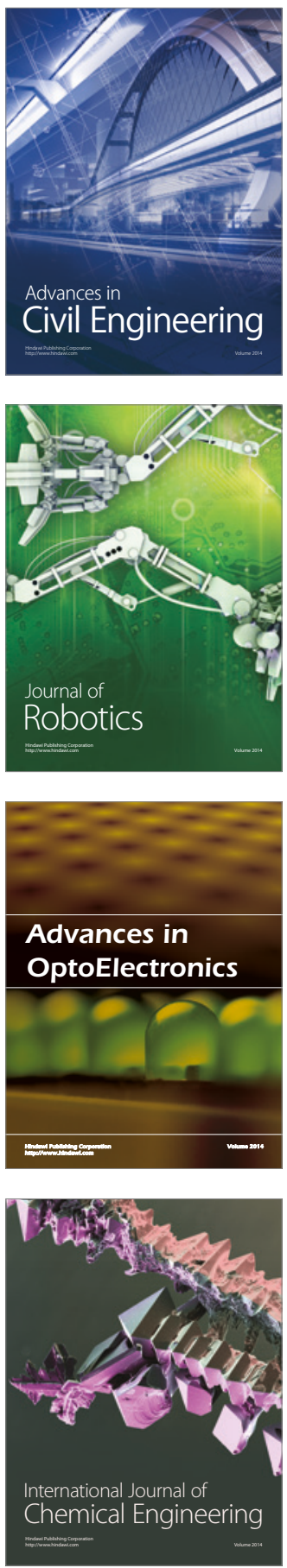

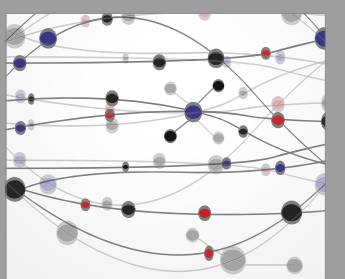

The Scientific World Journal

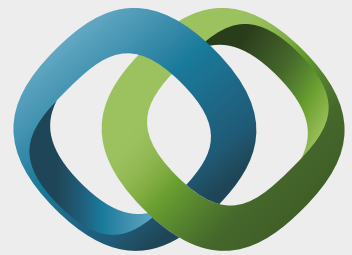

\section{Hindawi}

Submit your manuscripts at

https://www.hindawi.com
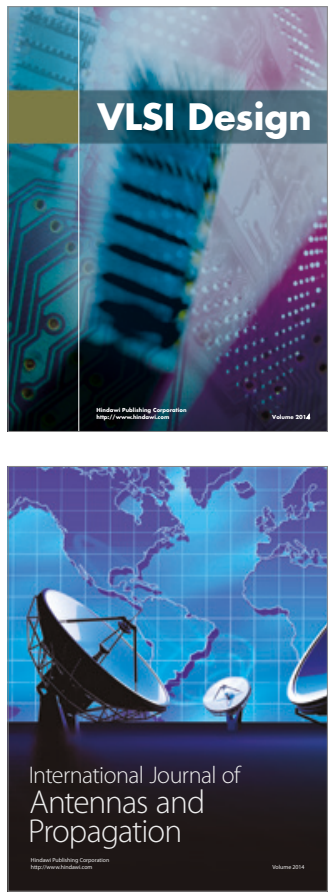

\section{Rotating}

Machinery
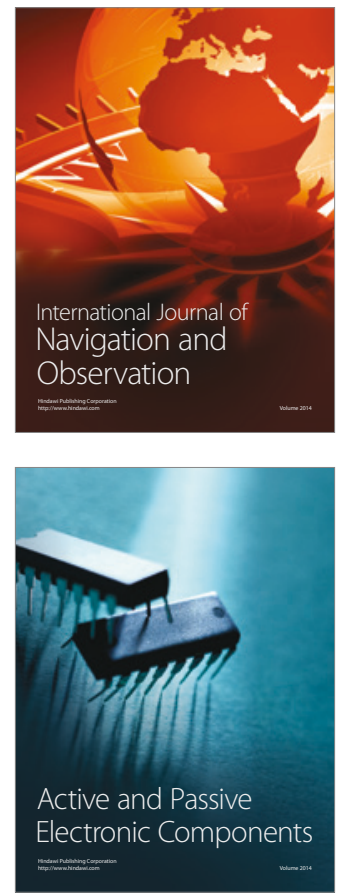
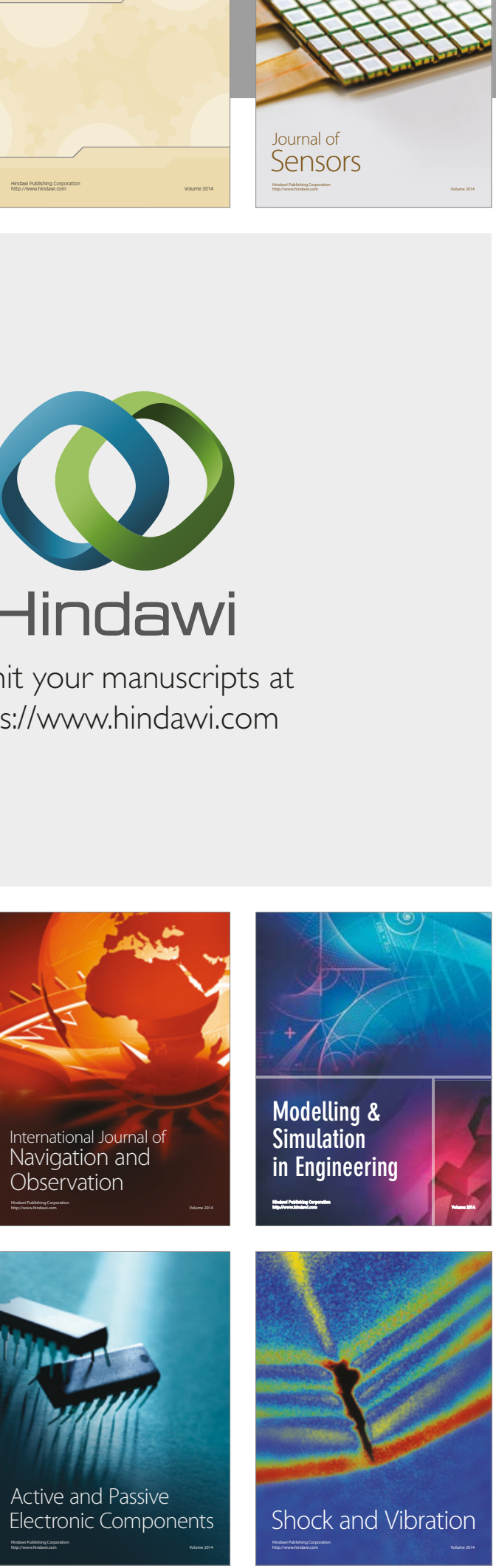
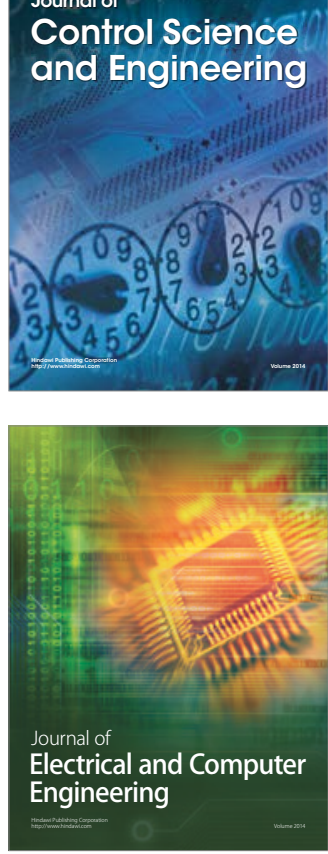

Distributed

Journal of

Control Science

and Engineering
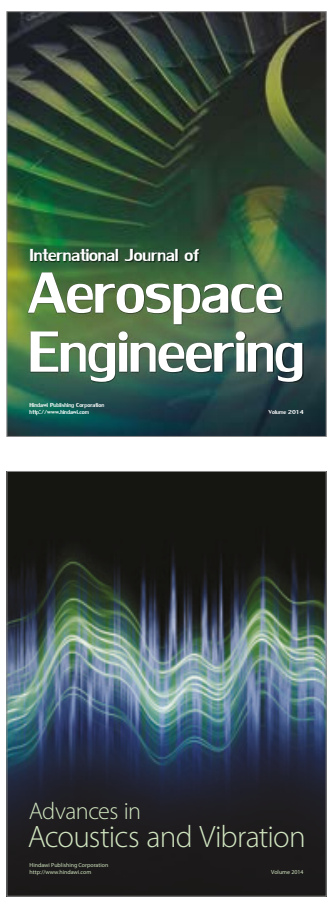

Sensor Networks 